INVESTIGATION BIOMEDICAL CORROSION OF IMPLANT ALLOYS IN PHYSIOLOGICAL ENVIRONMENT

\author{
NABAA S. RADHI ${ }^{1}$ \& ZAINAB AL-KHAFAJI ${ }^{2}$ \\ ${ }^{1}$ Lecturer of Materials College Engineering, University of Babylon, Hilla, Iraq \\ ${ }^{2}$ Information Technology Center, Al-Mustaqbal University College, Babylon, Iraq
}

\begin{abstract}
A biomaterial could be any material, which is designed for medical application inside human body for medical purposes such as treat, augment, repair or replace a tissue function of the body. And, these materials became very common in the ten recent years, and Ni-Ti alloys is considered as one of the metals that is used for biomedical applications. For long period, the biomaterials are very limited materials and these materials are very expensive such as bioinert titanium based alloys, stainless steel, alumina and zirconia ceramics. This research study focuses on the corrosion properties of both samples (Titanium and Stainless steel) in different corrosive environments such as NaCl, $\mathrm{H}_{2} \mathrm{SO}_{4}$ and $\mathrm{NaF}$, and investigates the microstructure before and after corrosive environments. And then, measuring the surface roughness with and without corrosive environments. Finally, XRD for both titanium and stainless steel samples are tested.
\end{abstract}

KEYWORDS: Biocompatible, Bioinert, Biomaterials, Biomedical, Implants \& XRD

Received: May 08, 2018; Accepted: May 29, 2018; Published: Jul 04, 2018; Paper Id.: IJMPERDAUG201827

\title{
INTRODUCTION
}

Due to increase in the need of body replacement parts (hard tissue) that get damaged due to heath issues or accidents, various metal had been used in many body parts like hip joints and knee joints, also bone plates, bolts, spinal fixation devices that are used as fracture healing aids, as well as used in dental planting. And, the reasons of this wide application for the metals inside human body are excellent mechanical characteristics and the metal resistance against corrosion. In addition to pure metals, some metallic alloys also used to perform an active role in producing devices parts like vascular stents, the wire of guiding in catheter, arch-wires of orthodontic and cochlea planting. And, to consider planting of the part in vivo environment is successful, the part must be biocompatible with the vivo environment, because metallic implant can be corroded in this environment (Williams, 1982). The corrosion of the implants have bad consequences such as the disintegration of the planting material itself, and this problem will weaken or hurt the planting, in addition to that the corrosion products have a harmful effect on the surrounding tissues and organs.

\section{Stainless Steels}

The stainless steel type 18-8 (type 302 in modern classification) was the first stainless steel types that are used for planting in human body, and this type of stainless steel is stronger than vanadium steel as well as more corrosion resistant. On the other hand, the experiments show that vanadium steel is corroded severely in vivo environment, for this reason, it is no longer applied in plantings. The development of stainless steel led to 
introduce 18-8sMo stainless steel, which has a small amount of molybdenum. This type is known as 316, which has good resistance against corrosion in salted water, especially in chloride solution. Later on, the carbon content was reduced from $0.08 \%$ to $0.03 \%$, and the chromium is $11 \%$ in stainless steel type 316 to improve the resistance against corrosion by chloride solution, and it became called as $316 \mathrm{~L}$ stainless steel.

\section{Pure Ti and Ti Alloys}

The first attempt to apply titanium as plantings in vivo returns to late 1930s. The good indicators of these plantings in cat femurs were stainless steel and Vitallium (CoCrMo alloy). Titanium has very good properties like lightness and other mechano-chemical characteristics which make it suitable for vivo plantings as seen in Table (1).

Table 1: Specific Gravities of Metallic Planting Alloys

\begin{tabular}{|c|c|c|c|c|c|}
\hline Alloys & Ti and Ti Alloys & Stainless Steel (316) & CoCrMo & CoNiCrMo & NiTi \\
\hline Density $\left(\mathrm{g} / \mathrm{cm}^{3}\right)$ & 4.5 & 7.9 & 8.3 & 9.2 & 6.7 \\
\hline
\end{tabular}

The term Osseo integration is referred to direct contact between viable remodeled bone and planting without any intervening for soft tissue. And, there are many factors that effect on the apposition of bone to the implant and on the bone implant, inter facial pull out strength and the titanium alloys surface roughness are one of these factors. The increasing of surface roughness average will increase the interfacial shear strength, where increase in roughness from $(0.5$ to 5.9$) \mu \mathrm{m}$ improve the shear strength from (0.48 to 3.5) Mpa, respectively (Feighan et al., 1995). As well as, the rough surfaces are better than the smooth one in highest levels of osteoblast cell attachment which are obtained (Keller et al., 1994). In addition to that, the heat treatment for titanium surface was changed chemically by producing TiO2 hydrogel layer above the $\mathrm{TiO} 2$ layer, as shown in Figure 1. The TiO2 hydrogel layer could induce the formation of apatite crystal (Kim et al., 1996). Generally, the rougher surfaces allow to lower cell numbers to produce, decreased rate of cellular proliferation, and increased matrix production compared to smooth surface. Bone formation appears to be strongly related to the presence of transforming growth factor $\beta 1$, in the bone matrix (Kieswetter et al., 1996).

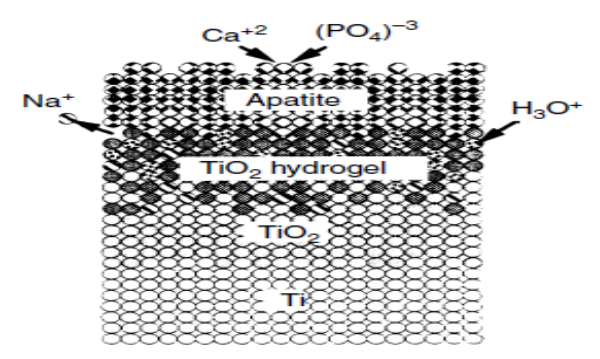

Figure 1: Chemical Changes for Titanium Surface after Heat Treatment (Kim Et Al., 1996)

\section{EXPERIMENTAL WORK AND PROCEDURE}

It is to involve the materials and equipment that are used in this work, and the sequence of operations and tests that have been accomplished.

The base alloy used in this work are stainless steel and titanium alloy, and all the above alloys should be of high purity (99.9 wt \%), because they are for human use, and any undesirable elements may cause side effects on the human health. 
The materials and alloys that are used in this work are:

- $\quad$ High purity titanium alloy of 99.9 wt $\%$, which was analyzed by XRD.

- $\quad$ Stainless steel has the purity of $99.9 \mathrm{wt} \%$, which was analyzed by XRD.

- $\mathrm{NaCl}$ has purity of $99.8 \mathrm{wt} \%$

- $\mathrm{NaF}$ of purity 99.99 wt\% purchased from (Fluka Company).

- $\mathrm{H}_{2} \mathrm{SO}_{4}$ high purity of $99.99 \mathrm{wt} \%$.

\section{Preparation of Samples}

The titanium and stainless steel specimens are cut into square shape with dimension (10*10) mm, and grinding to prepare for testing which include:

\section{X-Ray Diffraction Analysis}

This analysis has been carried out on both titanium alloy and stainless steel to identify the existing phases in the samples. The X-ray diffraction device used is Lab, XRD-6000, Shimadzu supplied with single wave length $\mathrm{Cu}-\mathrm{K} \alpha$ is 1.54 $\mathrm{A}^{\mathrm{o}}$, with nickel filter.

\section{Microstructure and Observation}

The microstructure of specimens of both titanium alloy and stainless steel have been observed and studied using optical microscope, the specimens were taken from each alloy and cold mounted, then wet ground using different grades of emery papers $(180,220,400,800,1000,1200)$, the grinding operations were achieved using a rotary disk machine. The microstructure took for specimens before and after corrosion test in different electrolyte solution was observed using optical microscope type (Nikon, Eclipse, ME 600 L, made in Japan).

\section{Corrosion Test}

In this work, there are three types of corrosion solution, which have been imbedded in the samples of stainless steel and titanium alloys. The electrolyte solutions used in corrosion tests, whose composition is shown in Table (2).

Before imbedding the samples in each electrolyte solution, we take the original weights and original surface areas, then after each 24 hour will go out to these samples from electrolyte solution and washing with distilled water and alcohol, then drying by hot air, finally taken the weight by using sensitive balance, and put each sample in the same electrolyte solution, which was taken from it. After 15 days, calculated the corrosion rate for each sample from this formula:

$$
\text { C. } R=\Delta w / A * t
$$

Whereas:

C.R: Corrosion Rate.

$\Delta \mathrm{w}$ : Weight Change (g).

A: Original Area $\left(\mathrm{mm}^{2}\right)$.

t: Time (days). 
Table 2: The Composition of Electrolyte Solution

\begin{tabular}{|c|l|c|}
\hline No. & Constituent & Concentration \\
\hline $\mathbf{1}$ & $\mathrm{NaCl}$ & $5 \%$ \\
\hline $\mathbf{2}$ & $\mathrm{NaF}$ & $5 \%$ \\
\hline $\mathbf{3}$ & $\mathrm{H}_{2} \mathrm{SO}_{4}$ & $10 \%$ \\
\hline
\end{tabular}

\section{Surface Roughness Test}

In this test, the roughness of the samples surfaces for both titanium alloy and stainless steel have been observed and studied by using surface roughness tester, the surface roughness was taken for specimens before and after corrosion test in different electrolyte solution.

\section{RESULT AND DISCUSSIONS}

\section{X-Ray Diffraction}

This test was conducted on the specimens of stainless steel and titanium alloys to determine the existing phases in each specimen. The range of the diffraction angle $\left(2 \theta^{\circ}\right)$ was $\left(20^{\circ}-70^{\circ}\right)$, the resulting phases are explained below.

\section{X - Ray Diffraction}

X-ray diffraction analyses of stainless steel have been studied, in order to identify metal used in this study, as illustrated in figure (2) and table (3).

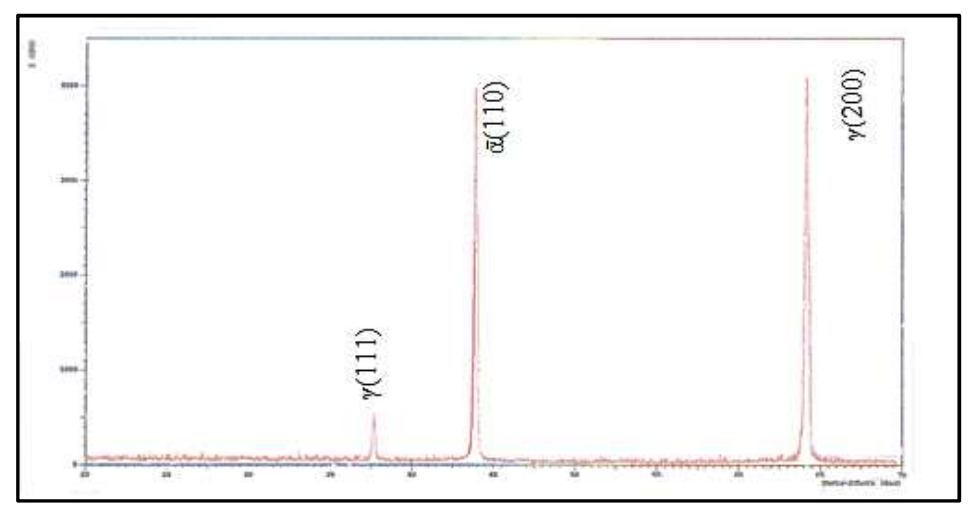

Figure 2: Illustrates X-Ray Diffraction Results for Stainless Steel Sample

Table 3: Illustrate $\left(\mathbf{2 \theta}^{\circ}\right)$, D-Spacing, Phases, And (Hkl) of Stainless Steel Samples

\begin{tabular}{|c|c|c|c|}
\hline $\mathbf{2 0}^{\mathbf{0}}$ & d (measured) $\mathbf{A}^{\mathbf{0}}$ & Phase & Hkl \\
\hline 37.6192 & 2.07336 & $\gamma$ & $(111)$ \\
\hline 44.4793 & 2.03524 & $\bar{\alpha}$ & $(110)$ \\
\hline 83.8239 & 1.22635 & $\gamma$ & $(200)$ \\
\hline
\end{tabular}

Figure (3) and table (3) show the phases that appear in this samples which $\gamma$ and $\bar{\alpha}$. While X-ray diffraction analyses of titanium has been studied, in order to identify metal used in this study, as illustrated in figure 3. and table (4). 


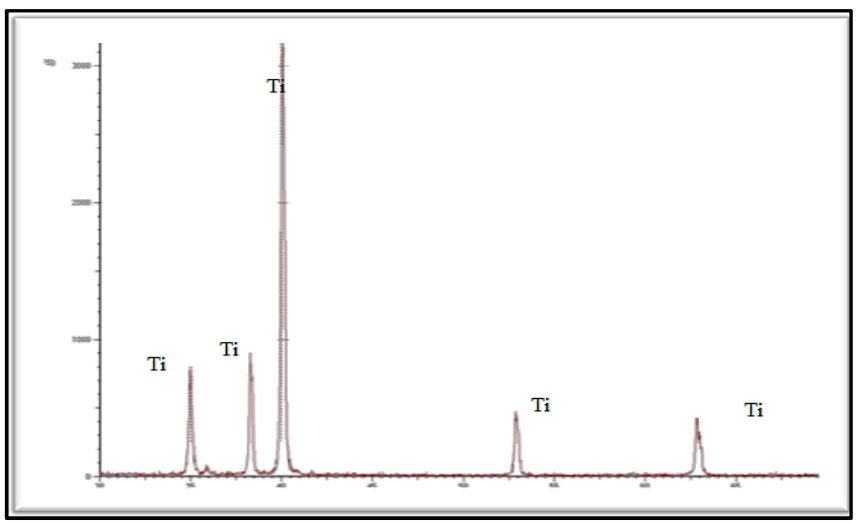

Figure 3: Illustrates X-Ray Diffraction Results For Titanium Sample

Table 4: Illustrates $\left(2 \theta^{\circ}\right)$, D-Spacing, Phases, And (Hkl) of Titanium Alloys

\begin{tabular}{|c|c|c|c|}
\hline $\mathbf{2 \theta}^{\mathbf{0}}$ & d (measured) $\mathbf{A}^{\mathbf{0}}$ & Phase & Hkl \\
\hline 35.000 & 2.5570 & $\mathrm{Ti}$ & $(100)$ \\
\hline 36.750 & 2.3420 & $\mathrm{Ti}$ & $(002)$ \\
\hline 40.255 & 2.2440 & $\mathrm{Ti}$ & $(101)$ \\
\hline 55.870 & 1.7260 & $\mathrm{Ti}$ & $(102)$ \\
\hline 65.755 & 1.4750 & $\mathrm{Ti}$ & $(110)$ \\
\hline
\end{tabular}

One of the analytical techniques used to detect the physical characteristics of materials, crystallographic structure information and chemical composition is X-ray diffraction (XRD). (XRD) is depending on scattered beam intensity of Xray that hit the specimen. And, one of the effective variables is wavelength, X-rays have wavelengths in the order of angstroms, and due to the range of typical interatomic distances in crystalline solids that is similar to the wavelength of $\mathrm{X}$ ray, and X-ray gives indication about the crystallographic structures of material (Miyazaki, 2009).

\section{Topographic Observation}

\section{Topographic Observation of Stainless Steel}

It can be observed from the below figures (5(a, b, c and d)), the surface of stainless steel samples can see cracks from corrosion and results from corrosion, which causes high value for roughness measurement tests than titanium alloys in same media.

Figure 4 (a) shows the topography of stainless steel sample after grinding without any electrolyte solution.

Figure 4(b) illustrates the topography of stainless steel sample after imbedded for 15 days in $5 \% \mathrm{NaCl}$ electrolyte solution.

Figure 4 (c) shows the topography of stainless steel sample after imbedded for 15 days in $5 \%$ NaF electrolyte solution.

Figure 4 (d) illustrates the topography of stainless steel sample after imbedded for 15 days in $10 \% \mathrm{H}_{2} \mathrm{SO}_{4}$ electrolyte solution. 


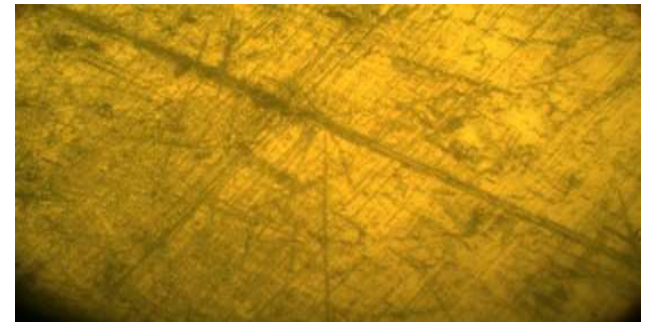

(a)

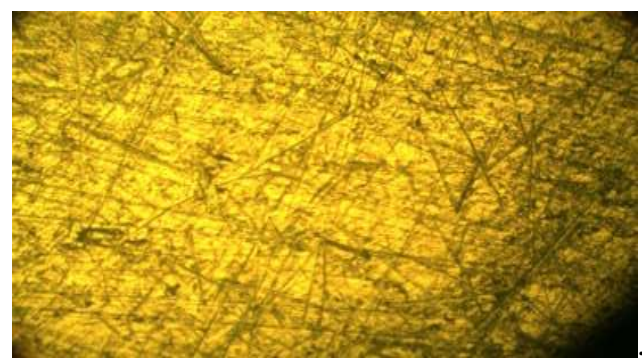

(c)

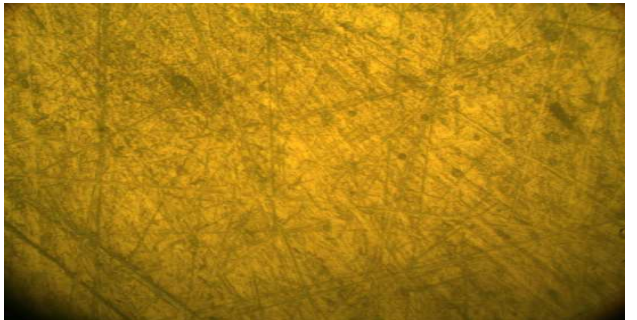

(b)

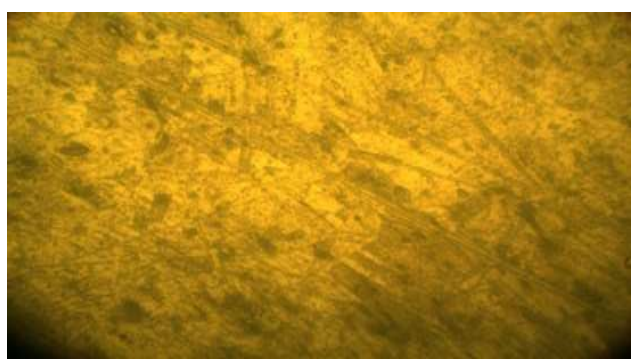

(d)

Figure 4: The Topography of Stainless Steel Sample after Grinding without any Electrolyte Solution and After Imbedded 15 Days In $5 \%$ Nacl, $5 \%$ Naf And $10 \% \mathrm{H}_{2} \mathrm{SO}_{4}$ Electrolyte Solutions

\section{Topographic Observation of Titanium Alloy}

From the below figures 5 ( $\mathrm{a}, \mathrm{b}, \mathrm{c}$ and $\mathrm{d}$ ), it is observed, the surface of titanium samples can see mini cracks from corrosion and results from corrosion, which causes low value for roughness measurement tests than stainless steel in same media.

Figure 5 (a) shows the topography of titanium sample after grinding without any electrolyte solution.

Figure 5 (b) illustrates the topography of titanium sample after imbedded for 15 days in $5 \% \mathrm{NaCl}$ electrolyte solution.

Figure 5 (c) shows the topography of titanium sample after imbedded for 15 days in $5 \%$ NaF electrolyte solution.

Figure 5 (d) illustrates the topography of titanium sample after imbedded for 15 days in $10 \% \mathrm{H}_{2} \mathrm{SO}_{4}$ electrolyte solution.

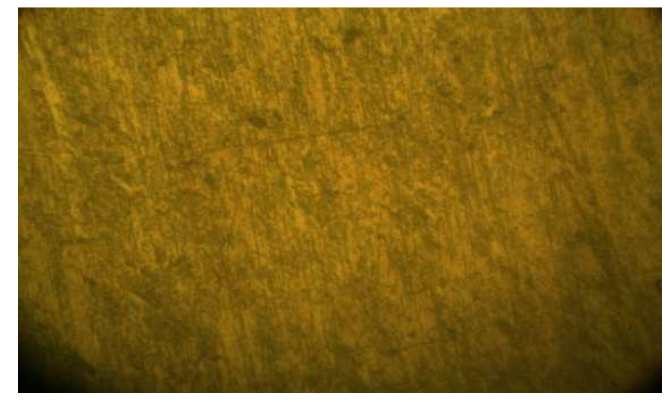

(a)

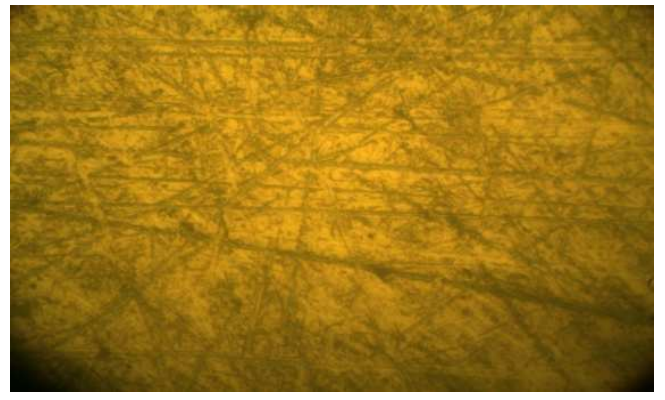

(b) 


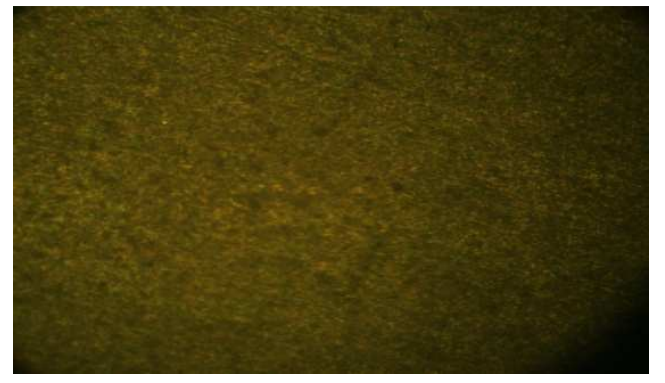

(c)

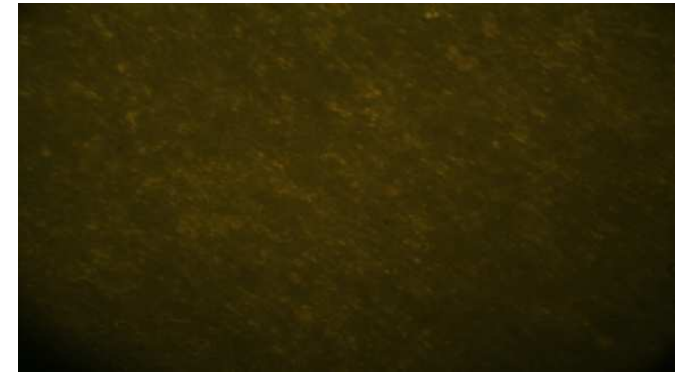

(d)

Figure 5: The Topography of Titanium Samples after Grinding Without any Electrolyte Solution and After Imbedded 15 Days In $5 \%$ Nacl, $5 \%$ Naf And $10 \% \mathrm{H}_{2} \mathrm{SO}_{4}$ Electrolyte Solutions

\section{Corrosion Test}

Chloride ion concentrations in the internal fluids are about seven times higher than its concentrations in oral fluids. Figure (7) illustrates the corrosion behaviour of the stainless steel and titanium samples after imbedded for 15 days in $5 \% \mathrm{NaCl}$ solution. The results illustrated titanium samples as the best corrosion resistant than stainless steel after imbedded for 15 days in $5 \% \mathrm{NaCl}$ solution, because it illustrated the availability of a thick film of oxide, consisting of $\mathrm{TiO}_{2}$. And, this oxide layer rise the resistance of local corrosion in solution containing $5 \% \mathrm{NaCl}$, compared with that of the stainless steel that made to conclude the precepts salts on the surface of sample after imbedded in $5 \% \mathrm{NaCl}$ that causes increase in weight.

From above figures ( $4 \mathrm{~b}$ and $5 \mathrm{~b}$ ), it can be observed that there are pits on the surface of stainless steel samples, because attack of these electrolyte solution to the surface effect values of surface roughness test, which is displayed in table $(5)$.

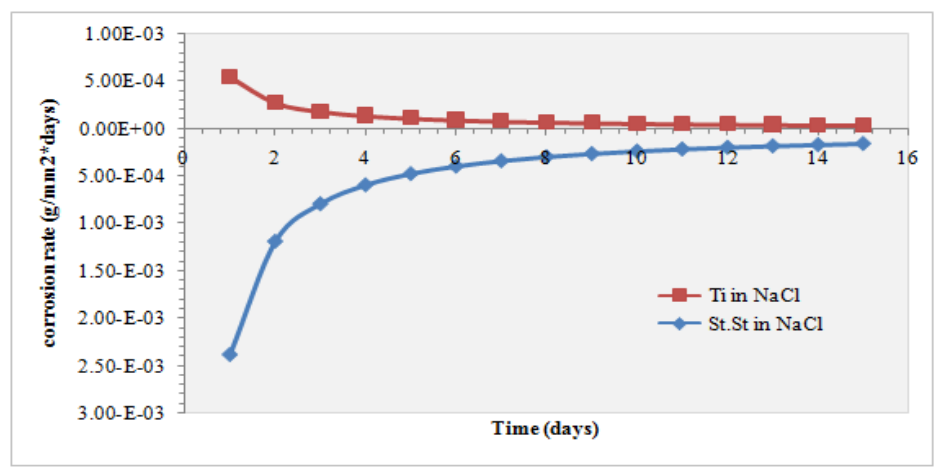

Figure 6: The Corrosion Behaviour of the Stainless Steel and Titanium Samples after Imbedded 15 Days in $5 \%$ Nacl, Solutions

Because of non-corrosive characteristics of titanium, it has excellent biocompatibility. But, due to the material passivity in vivo, it formed an adhesive oxide layer. For the previous reason, the sample was covered with the rutile type of $\mathrm{TiO} 2$ during the test. Figure (7) illustrates the corrosion behaviour of stainless steel and titanium samples after imbedded for 15 days in $5 \% \mathrm{NaF}$ solutions.

From above figures ( $4 \mathrm{c}$ and $5 \mathrm{c}$ ), it can be observed that pits are there on the surface of stainless steel and titanium samples, because attack of these electrolyte solution to the surface effect the values of surface roughness test, which is displayed in table (5). 


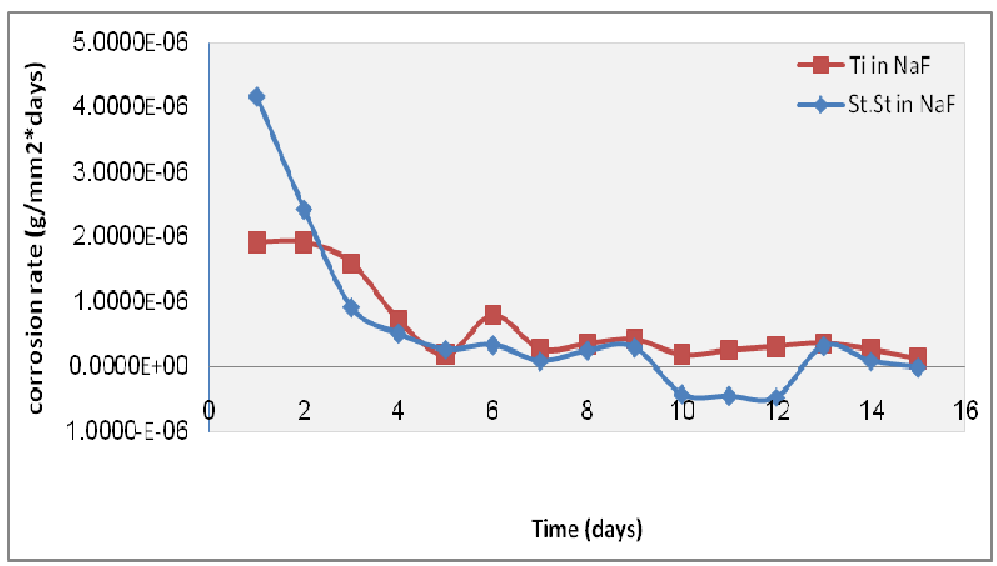

Figure 7: The Corrosion Behaviour of Stainless Steel And Titanium Samples After Imbedded 15 Days Inc Solutions

According to (Schiff, et.al. 2002), the pitting corrosion is caused by breaking and failure of the surrounding layer on the titanium and titanium alloys by fluoride ions attack. When immersing the titanium in the solutions containing fluoride, the titanium decay was recorded and the fluorine was found on the titanium surface. Figure (8) illustrates the corrosion behaviour of stainless steel and titanium samples after imbedded for 15 days in 10\% H2SO4 solution, which show non-corrosive properties for titanium and its alloys, for this reason and the other favourable properties such as low weight and high strength, they are used in medical applications widely.

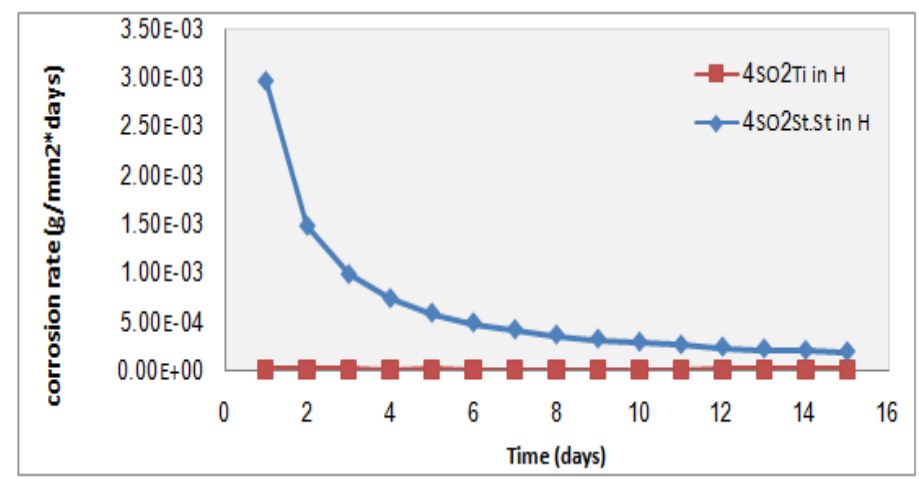

Figure 8: The Corrosion Behaviour of Stainless Steel and Titanium Samples After Imbedded 15 Days In $10 \% \mathrm{H}_{2} \mathrm{SO}_{4}$ Solutions

The concentrations of chloride ion in the internal fluids are about seven times higher chloride concentrations in oral fluids. A rich sodium chloride, added to large volumes of acidulated beverages (phosphoric acid) is considered a continuous source of corrosive despite the relatively short exposure. As well as, sulfur dioxide and hydrogen sulfide were found, in order to speed up the deformation and corrosion of planting metals. Moreover, from the above listed intraoral chemistry and electrochemistry, it is important to know how to simulate the intraoral environments, when the in vitro chemical or electrochemical corrosion test is prepared and carried out. Figure (9) illustrates the corrosion behaviour of stainless steel and titanium samples after imbedded for 15 days in $5 \% \mathrm{NaCl}, 5 \% \mathrm{NaF}$ and $10 \% \mathrm{H} 2 \mathrm{SO} 4$ solutions.. 


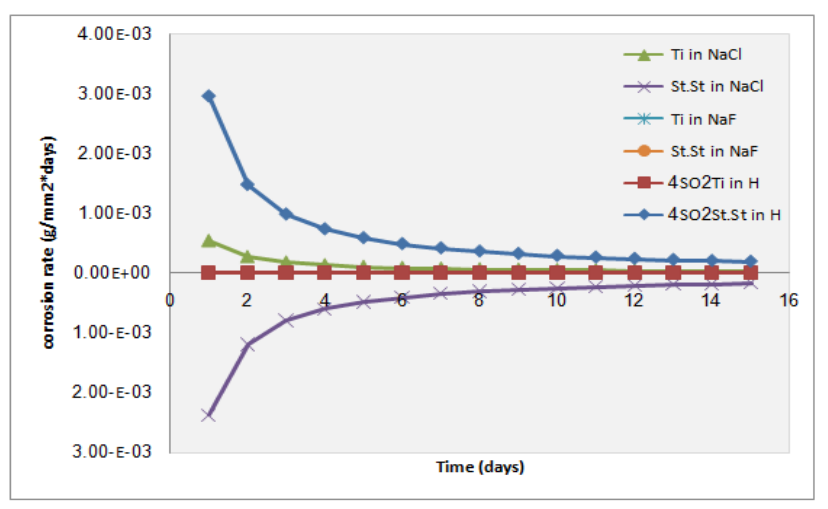

Figure 9: The Corrosion Behaviour of Stainless Steel and Titanium Samples After Imbedded 15 Days In $5 \%$ Nacl, $5 \%$ Naf And $10 \% \mathrm{H}_{2} \mathrm{SO}_{4}$ Solutions

\section{Surface Roughness Test}

Table (5) illustrates the surface roughness test before and after corrosion test for stainless steel and titanium samples.

\section{Table 5: Illustrate the Surface Roughness of Samples}

\begin{tabular}{|l|c|}
\hline \multicolumn{1}{|c|}{ Samples } & Roughness value $(\boldsymbol{\mu m})$ \\
\hline Stainless steel & 0.053 \\
\hline St.st. in $\mathrm{NaCl}$ & 0.049 \\
\hline St.st. in $\mathrm{NaF}$ & 0.123 \\
\hline St.st. in $\mathrm{H}_{2} \mathrm{SO}_{4}$ & 0.125 \\
\hline Titanium & 0.066 \\
\hline Ti. in $\mathrm{NaCl}$ & 0.120 \\
\hline Ti. in $\mathrm{NaF}_{2}$ & 0.091 \\
\hline Ti. in $\mathrm{H}_{2} \mathrm{SO}_{4}$ & 0.072 \\
\hline
\end{tabular}

\section{CONCLUSIONS}

This work included the compartment of Titanium and stainless steel by surface roughness, topography and corrosion test in different media, such as $\mathrm{NaCl}, \mathrm{NaF}$ and $\mathrm{H}_{2} \mathrm{SO}_{4}$, and the conclusions are as follows

- The results of corrosion illustrates titanium alloy as the best of stainless steel in different corrosion media.

- The surface roughness and topographic tests show that the titanium is the best, when compared with stainless steel.

\section{ACKNOWLEDGMENTS}

The Ministry of Higher Education and Babylon University in Iraq are gratefully acknowledged. The experimental part was performed in the laboratory of Babylon University.

\section{REFERENCES}

1. Assad, M., Lombardi, S., Berneche, S., Desrosiers, E.A., Yahia, L.H. and Rivard, C.H., 1994. Assays of cytotoxicity of the Nickel-Titanium shape memory alloy. In Annales de chirurgie (Vol. 48, No. 8, pp. 731-736).

2. Black, J. 1992. Biological Performance of Materials, Fundamentals of Biocompatibility, 2nd Ed., New York, NY: Marcel Dekker, Inc., pp. 73-91. 
3. Jones, D.A., 1996. Principles and Prevention of Corrosion. second.Rose Kerman.

4. Filip, P., Lausmaa, J., Musialek, J. and Mazanec, K., 2001. Structure and surface of TiNi human implants. Biomaterials, 22(15), pp.2131-2138.

5. Fontana and Green, 1978. Corrosion Engineering. McGrow-Hill Book Company.

6. Scully, J. C., 1990.The Fundamentals of Corrosion, ThirdEdition, BPCC Wheaton's LTD, United Kingdom.

7. Joyce Y. Wong, Joseph D. Bronzino, 2007. Biomaterials, CRC Press, London.

8. ML, Bubarai. "Response of Morphological and Physiological Characteristics Of Rice (Oryza Sativa L.) to Inorganic Fertilizer (Npk) Application: A Review." (2018).

9. Shreir, L.L., Jarman, R.A. and Burstein, G.T., 2000. Corrosion Metal/Environment Reactions, vol. I. IButterworth-Heinemann, Great Britain.

10. Sarkar, N.K., Moiseyeva, R., Berzins, D.W. and Osborne, J.W., 2000. Long-term corrosion of a Ga-containing restorative material. Dental Materials, 16(2), pp.97-102.

11. Desai, S., Bidanda, B. and Bártolo, P., 2008. Metallic and ceramic biomaterials: current and future developments. In BioMaterials and Prototyping Applications in Medicine (pp. 1-14). Springer, Boston, MA.

12. Aruna, S. Desai, and Rao Srinath. "Effect of Gamma Radiation on Germination and Physiological Aspects of Pigeon Pea (Cajanus Cajan (L.) Millsp). Seedlings." (2014).

13. Miyazaki, S., Fu, Y.Q. and Huang, W.M. eds., 2009. Thin film shape memory alloys: fundamentals and device applications. Cambridge University Press.

14. Schiff N, Grosgogeat B, Lissac M, Dalard F, 'Influence of fluoride content and $p H$ on

15. S.M. Dunne, and R. Abraham, 2000. A Study into the Performance of Gallium-Based Restorative Material, Br. Dent. J. Vol. 189, pp310-313.

16. Williams, D. F., 1982. Biocompatibliity in Clinical Practice (Boca Raton, FL: CRC Press). 